\title{
Potencial para o biocontrole de Botrytis cinerea por leveduras em sistema integrado de cultivo de lírio
}

\author{
Maria Augusta de Camargo Ferraz Machado(1) e Wagner Bettiol ${ }^{(2)}$
}

(1)Universidade Federal de São Carlos, Centro de Ciências Agrárias, Rodovia SP 330, Km 174, CEP $13600-970$ Araras, SP. E-mail: gutaagro@yahoo.com.br (2)Embrapa Meio Ambiente, Caixa Postal 69, CEP 13820-000 Jaguariúna, SP. Email: bettiol@cnpma.embrapa.br

Resumo - O objetivo deste trabalho foi comparar uma população de leveduras do filoplano de lírio de um sistema convencional de cultivo com outra de sistema integrado, além de avaliar o antagonismo da levedura Sporidiobolus pararoseus a Botrytis cinerea. A comunidade de leveduras foi estimada pelo método da queda dos balistoporos nos terços inferior, médio e superior das plantas, bem como nas faces adaxial e abaxial das folhas. Nos discos de folhas de plantas do sistema integrado, foi alta a presença da população de leveduras, tendo sido maior na face adaxial das folhas do terço médio das plantas. Para avaliação do antagonismo, foram aplicadas aos discos de folhas as concentrações de $10^{5}, 10^{6}$ e $10^{7}$ células $\mathrm{mL}^{-1}$ da levedura, em três períodos de inoculação: 24 horas antes; simultânea a; e 24 horas após a inoculação de $10^{4}$ esporos $\mathrm{mL}^{-1}$ de $B$. cinerea. A incidência, a percentagem de área de discos colonizados e a esporulação de $B$. cinerea foram avaliadas por meio de diagrama de notas, a partir do quarto dia após a inoculação. Todas as concentrações da levedura reduziram a esporulação de $B$. cinerea nos discos de folha, em comparação à testemunha, e a concentração de $10^{7}$ esporos $\mathrm{mL}^{-1}$ foi a mais eficiente.

Termos para indexação: Lilium, Sporidiobolus pararoseus, controle biológico, comunidade de levedura, sistema convencional, sistema integrado de produção.

\section{Potential control of Botrytis cinerea by yeasts in an integrated cultivation system of lilies}

\begin{abstract}
The objective of this study was to compare a population of phylloplane yeasts in lilies cultivated in a conventional cultivation system to other lilies in an integrated system, as well as to evaluate the antagonism of Sporidiobolus pararoseus to Botrytis cinerea. The yeast community was estimated by the spore-fall method in the lower, middle and upper thirds of the plants, as well as in the abaxial and adaxial leaf surfaces. The yeast population was high on the leaf discs of the plants from the integrated system, and it was higher on the adaxial surface and on leaves from the middle third of the plants. To evaluate yeast antagonism, concentrations of $10^{5}, 10^{6}$ and $10^{7}$ cells $\mathrm{mL}^{-1}$ were sprayed on the leaf discs in three inoculation times: 24 hours before; simultaneously; and 24 hours after inoculation with $B$. cinerea at a concentration of $10^{4}$ spores $\mathrm{mL}^{-1}$. The incidence and percentage of disc tissue area colonized and of $B$. cinerea sporulation were evaluated through a category scale, starting from the fourth day after the inoculation. All yeast concentrations reduced $B$. cinerea sporulation on the leaf discs in comparison to the control, and the yeast concentration of $10^{7}$ cells $\mathrm{mL}^{-1}$ was the most effective.
\end{abstract}

Index terms: Lilium, Sporidiobolus pararoseus, biological control, yeast community, conventional system, integrated production system.

\section{Introdução}

As leveduras presentes no filoplano colonizam as folhas desde o início de seu desenvolvimento, formam uma barreira na superfície foliar e são responsáveis pelo controle biológico natural de diversas doenças (Fokkema et al., 1979; Buck \& Andrews, 1999). O potencial de leveduras para o controle de doenças de plantas foi estudado por diversos autores (Fokkema
\& Meulen, 1976; Luz, 1985; Pascholati, 1998; Buck, 2002; Helbig, 2002; Allen et al., 2004; Fialho, 2004; Zanardo et al., 2009).

Reduções de $50 \%$ ou mais na infecção causada por Septoria nodurum em folhas de trigo foi obtida com a aplicação de Sporobolomyces roseus, Aureobasidium pullulans e Cryptococcus laurentii var. florescens, residentes na filosfera de trigo (Fokkema \& Meulen, 1976). Luz (1985) verificou que leveduras do filoplano

Pesq. agropec. bras., Brasília, v.45, n.6, p.539-545, jun. 2010 
de trigo controlaram manchas fúngicas foliares de trigo, tanto em casa de vegetação quanto no campo. Cryptococcus albidus, uma levedura isolada de morango, reduziu a incidência e a densidade de conidióforos de Botrytis cinerea em 86 e 99\%, respectivamente, em avaliações em discos de folhas de morango (Helbig, 2002). O efeito de Saccharomyces cerevisae no controle de doenças de plantas foi demonstrado por Pascholati (1998) e Fialho (2004). Allen et al. (2004) verificaram a ação de leveduras contra B. cinerea, Rhizoctonia solani e Sclerotinia homeocarpa. Buck (2002) relatou uma redução no desenvolvimento de lesões, causadas por $B$. cinerea coinoculada com Rhodosporidium toruloides em gerânio (Pelargonium hortorum).

De acordo com Bettiol et al. (2009) e Droby et al. (2009), diversas leveduras (Aureobasidium pullulans, Cryptococcus albidus, Pantoea agglomerans e Metschnikowia fructicola) são registradas, em muitos países, como agentes de biocontrole de fitopatógenos (Botrytis, Penicillium, Rhizopus, Monilia, Sclerotinia e Erwinia amylovora). As leveduras agem principalmente por competição de nutrientes e indução de resistência (Fialho, 2004; Zanardo et al., 2009). Por serem eficientes colonizadoras de superfícies foliares, são capazes de consumir nutrientes mais rapidamente do que os fungos fitopatogênicos (Droby \& Chalutz, 1994). De acordo com Castoria et al. (1997), além da competição por nutrientes, as leveduras interagem diretamente com as hifas fúngicas e produzem enzimas líticas da parede celular. Esses mesmos autores relataram a atividade da glucanase em dois isolados de leveduras em presença de Penicillium expansum e Botrytis cinerea. Sharma et al. (2008) verificaram que Sporidiobolus pararoseus produziu toxinas que inibiram o crescimento de fungos. Segundo Bai et al. (2002), Sporobolomyces roseus corresponde, em muitos aspectos, à Sporobolomyces shibatanus, o anamórfico de $S$. pararoseus.

Segundo Valdebenito-Sanhueza (2000), o uso de fungicidas para o controle de fitopatógenos elimina parte da população de leveduras e, consequentemente, aumenta a disponibilidade de nutrientes para os patógenos. Gildemacher et al. (2004) verificaram redução na população das leveduras, em frutos de maçã pulverizados com os fungicidas captan e dithianon.
Atualmente, diversos agricultores recorrem a técnicas que permitem a produção com redução ou mesmo sem o uso de agrotóxicos, como a relatada para lírio por Wit et al. (2009). Botrytis elliptica é o agente causal da queima das folhas de lírio, que é a doença economicamente mais prejudicial à cultura. Entretanto, no caso do sistema apresentado por Wit et al. (2009), essa doença é mantida em níveis baixos, sem a necessidade do uso de fungicidas para o seu controle. Assim, foi levantada a hipótese de que as leveduras são uma das responsáveis por esse equilíbrio.

O objetivo deste trabalho foi comparar a população de leveduras do filoplano, de plantas de lírio de um sistema convencional, com uma outra população de plantas produzidas em sistema integrado, e avaliar o antagonismo de Sporidiobolus pararoseus a Botrytis cinerea.

\section{Material e Métodos}

Utilizaram-se lírios da variedade Orange pixie, no estádio de botão floral, de duas propriedades no Município de Holambra, SP: uma sob cultivo convencional e outra com produção integrada (Wit et al., 2009). No cultivo convencional, as plantas foram tratadas com mistura de diversos inseticidas e fungicidas, entre eles captan, iprodione, mancozeb, tiofanato metílico, mancozeb+metalaxyl, imidacloprid, abamectina, deltametrina e paration metílico, nas dosagens recomendadas. No sistema integrado, as plantas foram pulverizadas semanalmente com Trichoderma spp., Clonostachys rosea, Beauveria bassiana, Metharyzium anisopliae e Bacillus thuringiensis, além de biofertilizante, produzido aerobicamente com composto orgânico, melaço e húmus de minhoca a $10 \%$ e extratos de alho, pimenta e própolis, conforme recomendação (Wit et al., 2009).

A determinação da população e o isolamento das leveduras colonizadoras do filoplano foram realizados pela técnica de queda dos balistosporos ("spore-fall method") em meio de cultivo (Dowding \& Peacock, 1991). Para tanto, foram selecionadas sete plantas ao acaso, de cada tratamento, divididas em terço superior, médio e inferior para a realização dos estudos. Com auxílio de um furador de $0,9 \mathrm{~cm}$ de diâmetro, foram retirados dez discos das folhas de cada altura das 
plantas: terço inferior, médio e superior. Cinco discos de cada face das folhas - adaxial e abaxial - foram fixados, com auxílio de vaselina, em tampas de placas de Petri que continham, no fundo, o meio extrato de malte (15 g de extrato de malte, $12 \mathrm{~g}$ de ágar e $600 \mathrm{~mL}$ de água), em condições assépticas. As placas foram mantidas à temperatura ambiente por 24 horas, quando foram dados leves toques na tampa das placas para auxiliar a liberação dos balistosporos. A avaliação foi realizada após 72 horas, tendo-se contado o número de colônias de leveduras nas projeções dos discos, com auxílio de microscópio estereoscópico. Colônias de leveduras foram transferidas para placas de Petri, para purificação, e preservadas em meio sólido. Com as mesmas plantas, após uma semana, foi repetido o procedimento, para verificar possíveis alterações na comunidade de leveduras nas folhas.

A identificação das leveduras foi realizada por sequenciamento da região D1/D2, da subunidade maior do gene rRNA, conforme Medeiros et al. (2008).

Como as diferenças entre os sistemas de cultivo foram qualitativas, não foi realizada a análise estatística dos dados.

Para se determinar o antagonismo de Sporidiobolus pararoseus a Botrytis cinerea, foram utilizados lírios da variedade Orange pixie, produzidos no sistema integrado. Para tanto, o experimento foi constituído de 13 tratamentos com 3 repetições cada. A levedura foi aplicada nas concentrações de $10^{5}$, $10^{6}$ e $10^{7}$ esporos $\mathrm{mL}^{-1}$ e três períodos de dispensa, com aplicação de levedura antes, simultânea a e após a inoculação com $B$. cinerea, na concentração de $10^{4}$ esporos $\mathrm{mL}^{-1}$. Além desses, houve dispensa da levedura sem o patógeno, às três concentrações, e um tratamento somente com o patógeno.

Discos das folhas foram retirados e desinfestados com hipoclorito de sódio (1 min), álcool a 70\% (1 min) e água destilada esterilizada (1 min). Após a desinfestação, os discos foram separados por tratamento, no total de 30 discos cada, que foram transferidos para caixas gerbox. No terceiro dia após a inoculação do patógeno, foram colocados dez discos em placas de Petri com o meio PCA (paraquat cloranfenicol ágar), para cada tratamento. A primeira avaliação foi realizada quatro dias após a inoculação, e as demais avaliações a cada dois dias, até o décimo segundo dia. Para isso, foi utilizada uma escala com oito notas (Peng \& Sutton, 1991), adaptada por Morandi et al. $(2000 ; 2007)$, de acordo com as percentagens de áreas de discos colonizados por $B$. cinerea: $0,0 \% ; 1$, $0-3 \%$; 2, 3-6\%; 3, 6-12\%; 4, 12-25\%; 5, 25-37\%; 6, $37-50 \%$; e $7,>50 \%$, e foi calculada a área abaixo da curva de esporulação (AACE). As análises estatísticas foram realizadas utilizando-se o SAS (SAS Institute, 2003). As médias dos tratamentos foram comparadas pelo teste de Tukey, a 5\% de probabilidade.

Para estudar a inibição do crescimento micelial de $B$. cinerea por $S$. pararoseus in vitro, foi utilizada uma alça com células de $S$. pararoseus, para fazer uma estria em placas de Petri com $9 \mathrm{~cm}$ de diâmetro, que continha o meio BDA a $2 \mathrm{~cm}$ da borda das placas (Fialho, 2004). Um disco $(0,6 \mathrm{~cm})$ de meio de cultura BDA, que continha $B$. cinerea em pleno crescimento, foi posicionado na extremidade oposta da placa. O controle consistiu de uma placa com um disco de micélio do patógeno sem levedura. As placas foram mantidas em temperatura ambiente e, durante sete dias, foi acompanhado o crescimento micelial do fungo. Foi avaliada, também, a presença de halo de inibição. Utilizou-se o delineamento inteiramente casualizado com cinco repetições.

\section{Resultados e Discussão}

A comunidade de leveduras nas folhas de plantas de lírio produzidas no sistema sem o uso de agrotóxicos, em todas as alturas e faces das folhas avaliadas, foi significativamente maior do que as do sistema com uso de agrotóxicos (Figuras 1 A e 2 A). Transcorrida uma semana, o número de leveduras por discos de folhas de lírio, de plantas do sistema integrado, continuou superior aos do sistema convencional, que tendeu a zero em todas as alturas (Figura $1 \mathrm{~B}$ ).

A reduzida população de leveduras nas plantas de lírio do sistema convencional, em comparação à do sistema integrado, pode ser atribuída à sensibilidade dessas leveduras aos agrotóxicos, principalmente aos fungicidas. Teixidó et al. (1999) analisaram o impacto de fungicidas aplicados a maçãs e observaram redução significativa da população total de leveduras. Camatti-Sartori et al. (2006) isolaram leveduras de folhas de macieira nos sistemas convencional, integrado e orgânico e verificaram que a população de leveduras foi maior no sistema orgânico, em comparação aos outros dois sistemas. Valarini et al. 
(2007) verificaram que a população de levedura em folhas de ipê (Tabebuia sp.) reduzia-se, na medida em que se aproximava da região central da cidade.

Segundo Last \& Deighton (1965), conforme a idade da folha, há mudanças sucessivas no número de colônias de leveduras, que só aumenta depois que a folha atinge a primeira metade da sua vida. Essa informação está de acordo com o verificado no presente trabalho, em que se observou maior população de leveduras no terço mediano das plantas do sistema integrado (Figura $1 \mathrm{~A}$ ).
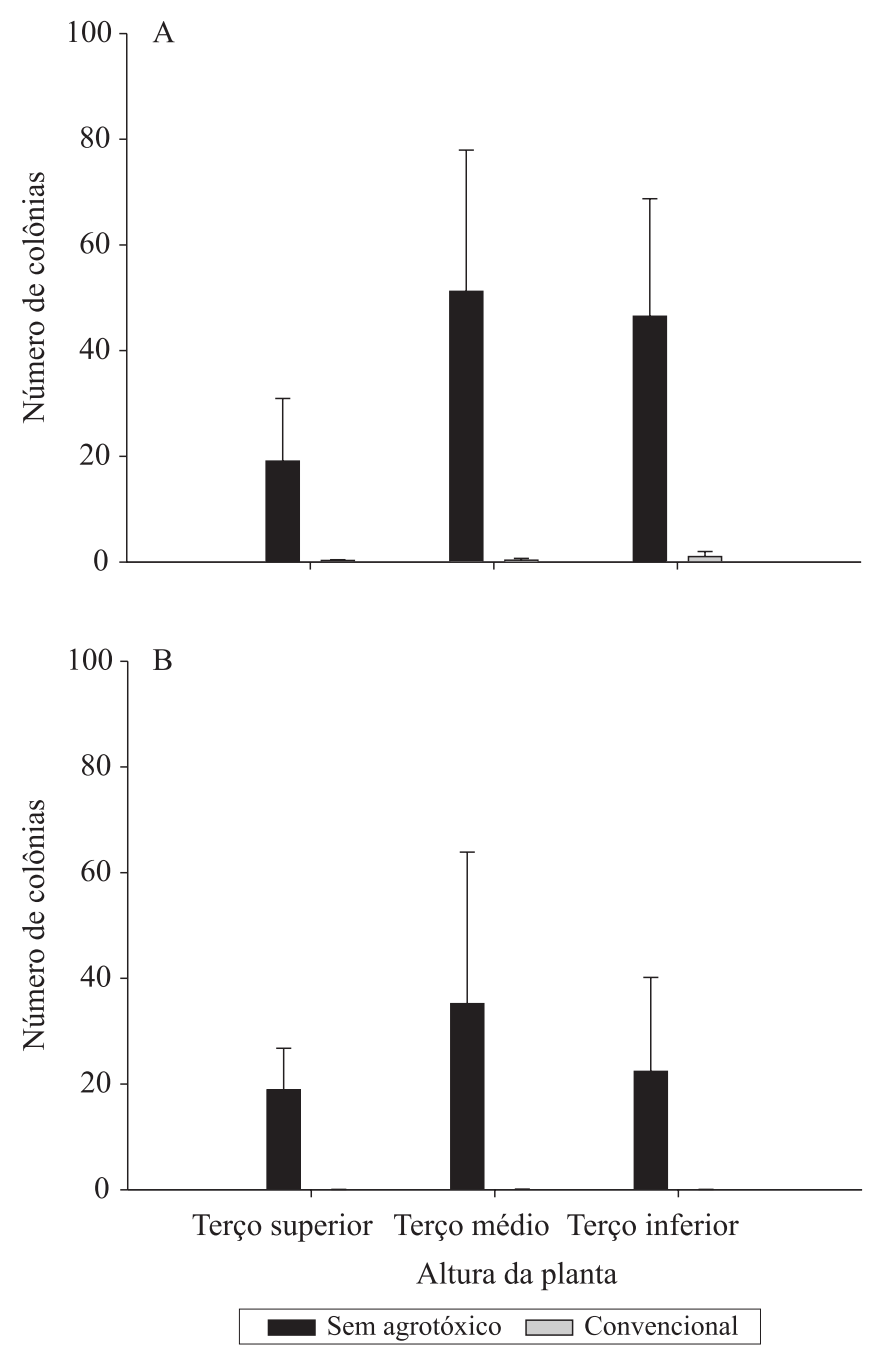

Figura 1. Número de colônias de leveduras, em discos de folhas de lírio originado de plantas produzidas sem uso de agrotóxicos e no sistema convencional, em relação à altura de planta, no momento da coleta (A) e uma semana após a primeira avaliação (B). As barras na vertical indicam o desvio-padrão.
A população de leveduras, para os dois sistemas, foi maior na face adaxial (Figuras $2 \mathrm{~A}$ e B). Entretanto, foi muito superior no sistema integrado. Em estudos sobre a distribuição de colônias de leveduras na superfície de folhas de gramíneas, Last \& Deighton (1965) não encontraram diferenças entre as faces adaxial e abaxial. Porém, esses mesmos autores encontraram diferenças em crisântemo, em que um número maior de organismos foi encontrado na abaxial em relação à face adaxial das folhas. Características de cada espécie de plantas devem interferir nesses resultados.
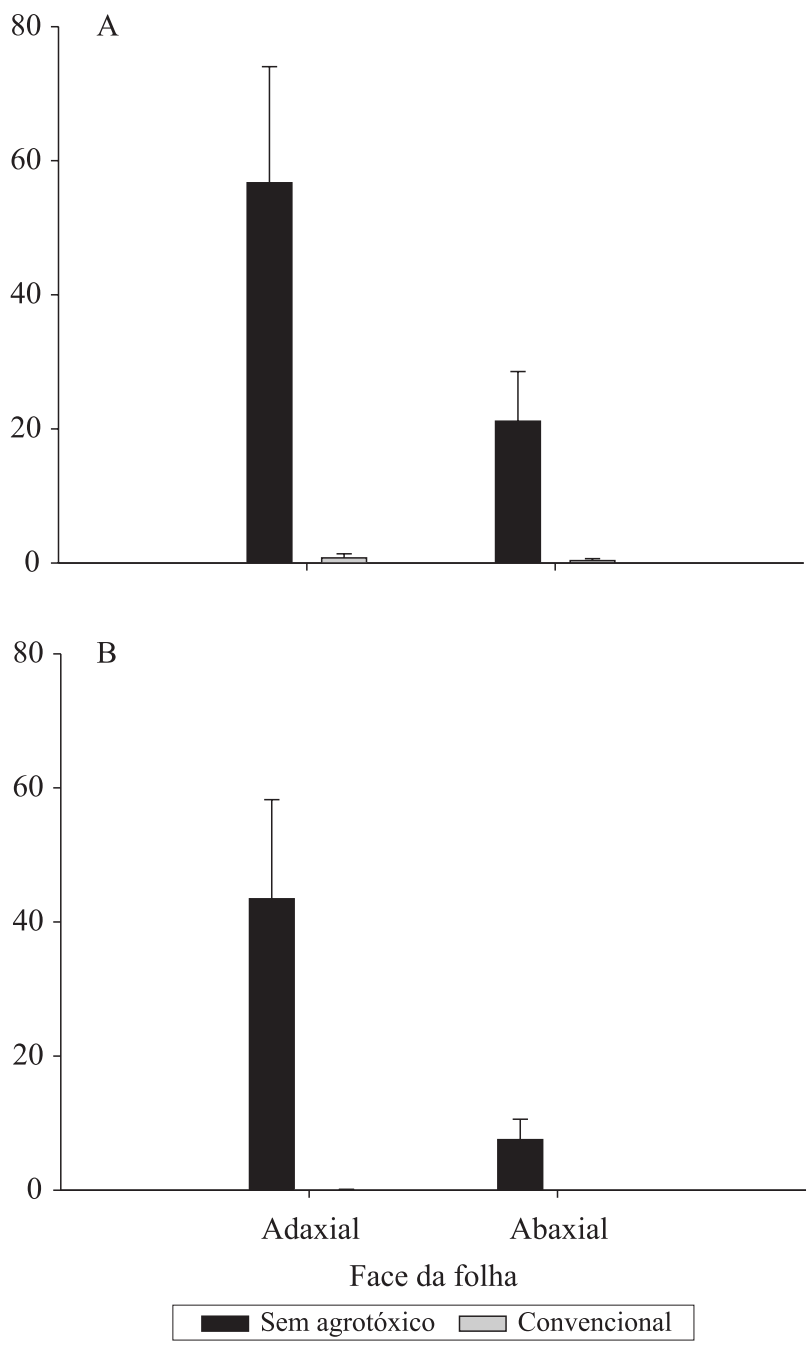

Figura 2. Número de colônias de leveduras, em discos de folha de lírio originado de plantas produzidas sem uso de agrotóxicos e no sistema convencional, em relação às faces adaxial e abaxial das folhas, no momento da coleta (A) e uma semana após a primeira avaliação (B). As barras na vertical indicam o desvio-padrão. 
Os isolados de levedura foram identificados como Sporidiobolus pararoseus. Esse gênero possui colônias de cor rosa e avermelhada e pode, muitas vezes, ser confundido com Sporobolomyces roseus. Segundo Fell \& Tallman (1981), o gênero Sporidiobolus foi classificado por Nyland como semelhante a Sporobolomyces, com exceção da presença de micélio dicariótico e teliosporos. No entanto, diferenciamse em graus de assimilação de carbono e nitrogênio (Bai et al., 2002). No caso de $S$. pararoseus, não há assimilação de nitrato (Statzell-Tallman \& Fell, 1998), e o contrário ocorre em $S$. roseus, em que há assimilação deste composto (Boekhout \& Nakase, 1998).

Com relação à área abaixo da curva de esporulação de $B$. cinerea, não houve diferença significativa entre os períodos de dispensa, mas, de modo geral, a aplicação da levedura antes, simultânea a e após a inoculação colaborou com a sua redução. A concentração de $10^{6}$ células $\mathrm{mL}^{-1}$, em todos os períodos de dispensa, não diferiu da testemunha (Figura 3 A). Na Figura 4, observa-se que, ao longo das cinco avaliações, a tendência foi de menor severidade da doença nos tratamentos que receberam a aplicação da levedura. A incidência de $B$. cinerea, nos discos de folha de lírio, foi reduzida em todos os tratamentos em relação à testemunha (Figura $3 \mathrm{~B}$ ), com exceção da levedura nas concentrações de $10^{6}$ e $10^{7}$ células $\mathrm{mL}^{-1}$, dispensadas antes da inoculação do patógeno. Esses resultados corroboram os de Droby \& Chalutz (1994) e El-Ghaouth et al. (2003), que afirmaram que a atividade antagônica é mais eficaz, quando a levedura é aplicada antes da infecção pelo patógeno.

Um dos principais mecanismos de ação de leveduras contra $B$. cinerea é a competição por nutrientes (Janisiewicz et al., 2000). Os resultados do presente trabalho indicam que $S$. pararoseus apresenta potencial para reduzir a incidência e severidade de Botrytis nas plantas de lírio, e que é fundamental manter elevada a sua população para atuar no controle biológico natural da doença, o que foi reportado também por Buck \& Andrews (1999), Buck (2002) e Sharma et al. (2008). Esses resultados indicam que o manejo integrado da cultura de lírio sem o uso de agrotóxicos, conforme descrito por Wit et al. (2009), mantém elevada a população de leveduras nas folhas das plantas.

Não foi verificada a formação de halo de inibição, quando $B$. cinerea foi desafiado pela levedura
S. pararoseus. Pode-se, portanto, afirmar que a levedura não inibiu o crescimento micelial de B. cinerea em comparação à testemunha . Isso mostra que essa levedura não agiu por meio de antibiose sobre $B$. cinerea, o que implica que a levedura deve possuir outro modo de ação sobre este fitopatógeno, sendo a competição o mais provável.
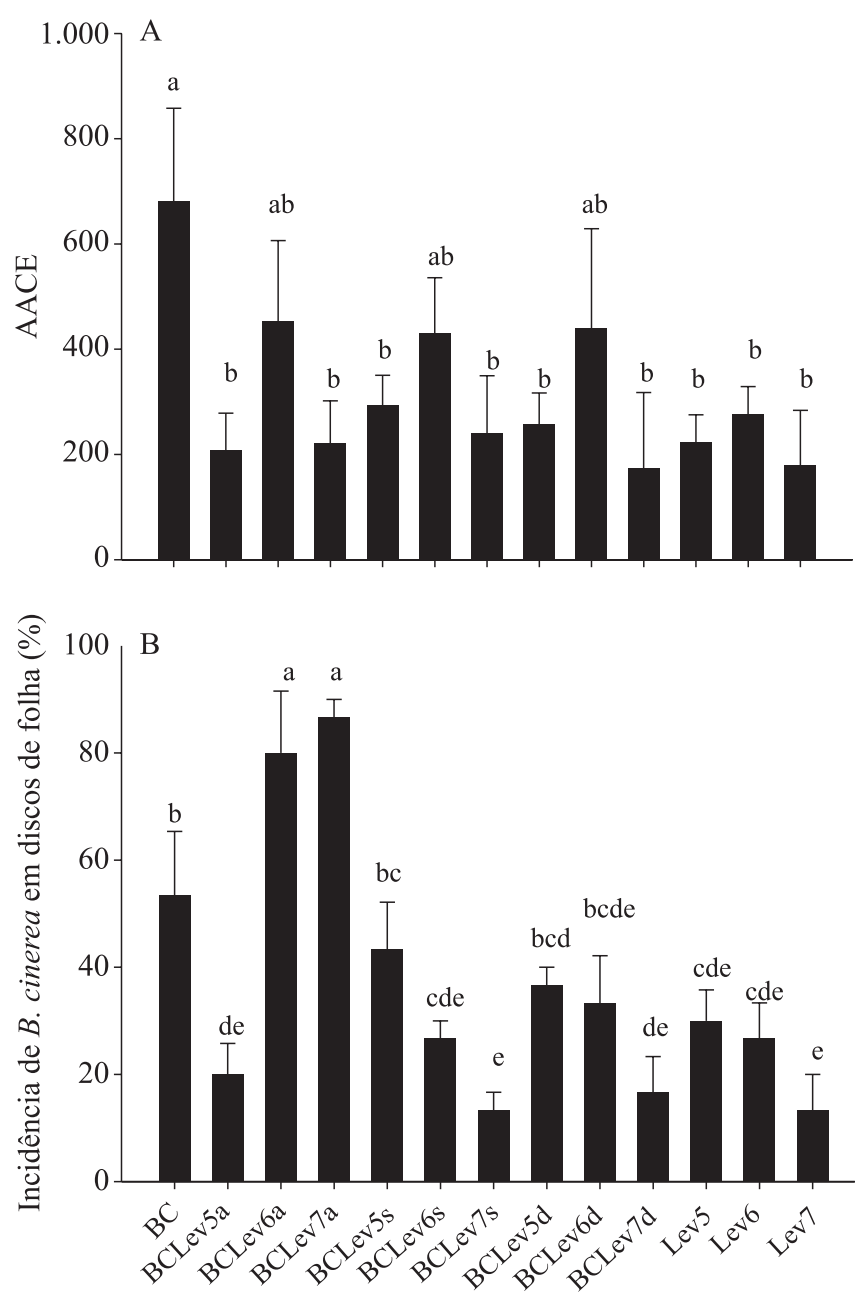

Figura 3. Efeito de Sporidiobolus pararoseus sobre a área abaixo da curva de esporulação (AACE) de Botrytis cinerea, em discos de folhas de lírio, dispensadas antes, simultaneamente e após a inoculação do patógeno (A), e incidência de $B$. cinerea em discos de folhas, no sistema integrado de produção (B). BC, B. cinerea; Lev 5, 6 e 7, levedura nas concentrações $10^{5}, 10^{6}$ e $10^{7}$ células $\mathrm{mL}^{-1}$; a, s, d, aplicação 24 horas antes, simultânea e 24 horas depois da inoculação de $B$. cinerea. Médias seguidas de letras iguais não diferem entre si, pelo teste de Tukey, a $5 \%$ de probabilidade. 


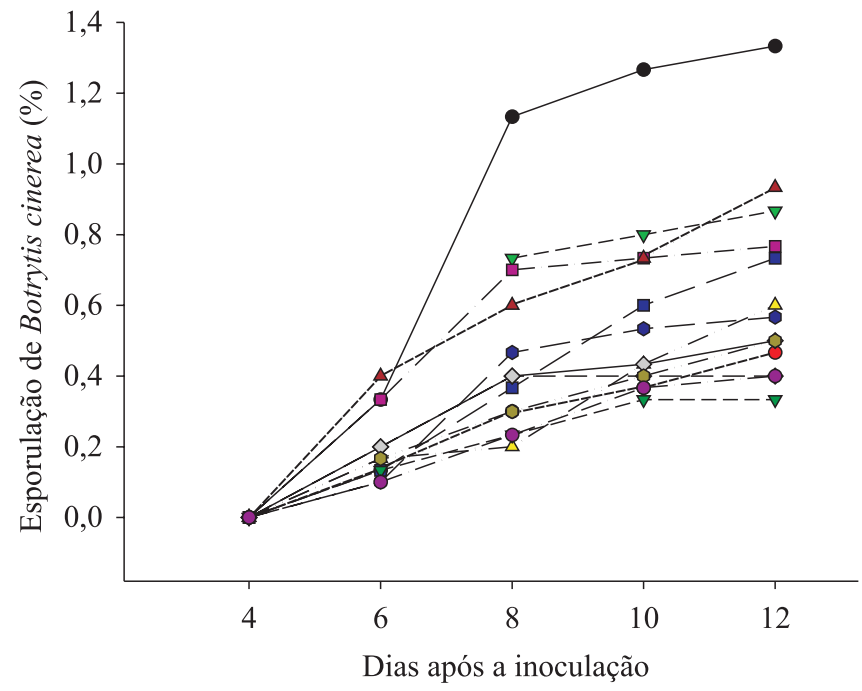

\begin{tabular}{|c|c|c|c|}
\hline$\longrightarrow$ & $\mathrm{BC}$ & $\diamond$ & BCLev5d \\
\hline -------০------ & BCLev5a & ----- $\Delta$------ & BCLev6d \\
\hline$--\nabla--$ & BCLev6a & $--\rightarrow--$ & BCLev7d \\
\hline$-\Delta--$ & BCLev7a & $-\cdots-\cdots$ & Lev5 \\
\hline$-\rightarrow-$ & BCLev5s & $-\rightarrow-$ & Lev6 \\
\hline$--\square--$ & BCLev6s & $--0--$ & Lev7 \\
\hline$-\diamond-$ & BCLev7s & & \\
\hline
\end{tabular}

Figura 4. Esporulação de Botrytis cinerea, em discos de folhas de lírio cultivado no sistema integrado, sem uso de agrotóxicos. BC, B. cinerea; Lev 5, 6 e 7, levedura nas concentrações de $10^{5}, 10^{6}$ e $10^{7}$ células $\mathrm{mL}^{-1} ; \mathrm{a}, \mathrm{s}, \mathrm{d}$, aplicação de levedura 24 horas antes, simultâneamente e 24 horas depois da inoculação de $B$. cinerea.

\section{Conclusões}

1. O manejo da cultura do lírio sem uso de agrotóxico mantém elevada a população de Sporidiobolus pararoseus, e o cultivo convencional reduz a população dessa levedura.

2. Sporidiobolus pararoseus, isolada das plantas de lírio produzidas no sistema integrado de cultivo, apresenta potencial para a redução de incidência e severidade de Botrytis cinerea.

3. Sporidiobolus pararoseus não inibe o crescimento micelial de Botrytis cinerea, e o modo de ação dessa levedura sobre o patógeno deve ser o de competição por nutrientes e espaço.

\section{Agradecimentos}

À Fundação de Apoio à Pesquisa Agrícola, a Johannes Petrus Wulfram de Wit e a Ronaldo Aluísio
Kievitsbosh, pela concessão de bolsa e fornecimento do material para realização dos experimentos. Ao Dr. Carlos Rosa, do Departamento de Microbiologia, da Universidade Federal de Minas Gerais, pela identificação do isolado de levedura.

\section{Referências}

ALLEN, T.W.; QUAYYUM, A.H.; BURPEE, L.L.; BUCK, J.W. Effect of foliar disease on the epiphytic yeast communities of creeping bentgrass and tall fescue. Canadian Journal of Microbiology, v.50, p.853-860, 2004.

BAI, F.; ZHAO, J.; TAKASHIMA, M.; JIA, J.; BOEKHOUT, T.; NAKASE, T. Reclassification of the Sporobolomyces roseus and Sporidiobolus pararoseus complexes, with the description of Sporobolomyces phaffii sp. nov. International Journal of Systematic and Evolutionary Microbiology, v.52, p.2309-2314, 2002.

BETTIOL, W.; MORANDI, M.A.B.; PINTO, Z.V.; PAULA JUNIOR, T.J. de; CORREA, E.B.; MOURA, A.B.; LUCON, C.M.M.; COSTA, J. de C. do B.; BEZERRA, J.L. Bioprotetores comerciais para o controle de doenças de plantas. Revisão Anual de Patologia de Plantas, v.17, p.111-147, 2009.

BOEKHOUT, T.; NAKASE, T. Sporobolomyces Kluyver \& van Niel. In: KURTZMAN, C.P.; FELL, J.W. (Ed.). The yeasts: a taxonomic study. $4^{\text {th }}$ ed. Amsterdam: Elsevier, 1998. p.828-843.

BUCK, J.W. In vitro antagonism of Botrytis cinerea by phylloplane yeasts. Canadian Journal of Botany, v.80, p.885-891, 2002.

BUCK, J.W.; ANDREWS, J.H. Role of adhesion in the colonization of barley leaves by the yeast Rhodosporidium toruloides. Canadian Journal of Microbiology, v.45, p.433-440, 1999.

CAMATTI-SARTORI, V.; SILVA-RIBEIRO, R.T.; VALDEBENITO-SANHUEZA, R.M.; ECHEVERRIGARAY, S.; PELlIZARI, D.; SILVA, E.M.; BOLDO, E.L.; SILVA, S.; GRAZZELLI, R.; BECKER, R.; PINTO, D.; AZEVEDO, J.L. de. Monitoramento de fungos epifíticos nos sistemas de produção orgânico, integrado e convencional da macieira. Revista Brasileira de Agroecologia, v.1, p.721-724, 2006.

CASTORIA, R.; DE CURTIS, F.; LIMA, G.; DE CICCO, V. $\beta$-1,3-glucanase activity of two saprophytic yeasts and possible mode of action as biocontrol agents against postharvest diseases. Postharvest Biology and Technology, v.12, p.293-300, 1997.

DOWDING, P.; PEACOCK, J. The use of leaf surface inhabiting yeasts as monitors of air pollution by sulphur dioxide. In: JEFFREY, D.W.; MADDEN, B. (Ed.). Bioindicators and environmental management. London: Academic Press, 1991. p.322-342.

DROBY, S.; CHALUTZ, E. Mode of action of biocontrol agents of postharvest diseases. In: WILSON, C.L.; WISNIEWSKI, M.E. (Ed.). Biological control of postharvest diseases: theory and practice. Boca Raton: CRC, 1994. p.63-75.

DROBY, S.; WISNIEWSKI, M.; MACARISIN, D.; WILSON, C. Twenty years of postharvest biocontrol research: is it time for a new paradigm? Postharvest Biology and Technology, v.52, p.137-145, 2009. 
EL-GHAOUTH, A.; WILSON, C.L.; WISNIEWSKI, M. Control of postharvest decay of apple fruit with Candida saitoana and induction of defense responses. Phytopathology, v.93, p.344-348, 2003.

FELL,J.W.;TALLMAN,A.S.Heterothallisminthebasidiomycetous yeast genus Sporidiobolus Nyland. Current Microbiology, v.5, p.77-82, 1981.

FIALHO, M.B. Efeito in vitro de Saccharomyces cerevisae sobre Guignardia citricarpa, agente causal da pinta - preta dos citros. 2004. 60p. Dissertação (Mestrado) - Escola Superior de Agricultura Luiz de Queiroz, Piracicaba.

FOKKEMA, N.J.; DEN HOUTER, J.G.; KOSTERMAN, Y.J.C.; NELIS, A.L. Manipulation of yeasts on field-grown wheat leaves and their antagonistic effect on Cochliobolus sativus and Septoria nodorum. Transactions of the British Mycological Society, v.72, p. 19-29, 1979.

FOKKEMA, N.J.; MEULEN, F. van der. Antagonism of yeastlike phyllosphere fungi against Septoria nodorum on wheat leaves. European Journal of Plant Pathology, v.82, p.13-16, 1976.

GILDEMACHER, P.R.; HEIJNE, B.; HOUBRAKEN, J.; VROMANS, T.; HOEKSTRA, E.S.; BOEKHOUT, T. Can phyllosphere yeasts explain the effect of scab fungicides on russeting of Elstar apples? European Journal of Plant Pathology, v.110, p.929-937, 2004.

HELBIG, J. Ability of the antagonistic yeast Cryptococcus albidus to control Botrytis cinerea in strawberry. Biocontrol, v.47, p.85-99, 2002.

JANISIEWICZ, W.J.; TWORKOSKI, T.J.; SHARER, C. Characterizing the mechanism of biological control of postharvest diseases on fruits with a simple method to study competition for nutrients. Phytopathology, v.90, p.1196-1200, 2000.

LAST, F.T.; DEIGHTON, F.C. The non-parasitic microflora on the surfaces of living leaves. Transactions of the British Mycological Society, v.48, p.83-99, 1965.

LUZ, W.C. da. Efeito de microrganismos do filoplano sobre as manchas fúngicas foliares do trigo. Fitopatologia Brasileira, v.10, p.79-84, 1985.

MEDEIROS, A.O.; KOHLER, L.M.; HAMDAN, J.S.; MISSAGIA, B.S.; BARBOSA, F.A.R.; ROSA, C.A. Diversity and antifungal susceptibility of yeasts from tropical freshwater environments in Southeastern Brazil. Water Research, v.42, p.3921-3929, 2008.

MORANDI, M.A.B.; MATTOS, L.P.V. de; SANTOS, E.R. dos; BONUGLI, R.C. Influence of application time on the establishment, survival, and ability of Clonostachys rosea to suppress Botrytis cinerea sporulation on rose debris. Crop Protection, v.27, p.77-83, 2007.

MORANDI, M.A.B.; SUTTON, J.C.; MAFFIA, L.A. Effects of host and microbial factors on development of Clonostachys rosea and control of Botrytis cinerea in rose. European Journal of Plant Pathology, v.106, p.439-448, 2000.

PASCHOLATI, S.F. Potencial de Saccharomyces cerevisiae e outros agentes bióticos na proteção de plantas contra patógenos. 1998. 123p. Tese (Livre Docência) - Escola Superior de Agricultura Luiz de Queiroz, Piracicaba.

PENG, G.; SUTTON, J.C. Evaluation of microorganisms for biocontrol of Botrytis cinerea in strawberry. Canadian Journal of Plant Pathology, v.13, p.247-257, 1991.

SAS INSTITUTE. SAS/STAT user's guide. Version 9.1. Cary: SAS Institute, 2003.

SHARMA, R.N.; MAHARSHI, R.P.; GAUR, R.B. Sporidiobolus pararoseus Fell \& Tallman - an antagonistic yeast with biocontrol potential. Current Science, v.95, p.1003-1004, 2008.

STATZELL-TALLMAN, A.; FELL, J.W. Sporidiobolus Nyland. In: KURTZMAN, C.P.; FELL, J.W. (Ed.). The yeasts, a taxonomic study. $4^{\text {th }}$ ed. Amsterdam: Elsevier, 1998. p.693-699.

TEIXIDÓ, N.; USALL, J.; MAGAN, N.; VIÑAS, I. Microbial population dynamics on Golden Delicious apples from bud to harvest and effect of fungicide applications. Annual of Applied Biology, v.134, p.109-116, 1999.

VALARINI, G.A.; MELO, I.S.; VALARINI, M.J.; VALARINI, P.J. Leaf yeasts as bioindicators of air pollution in southeastern Brazil. In: INTERNATIONAL CONFERENCE ON ENVIRONMENTAL SCIENCE AND TECHNOLOGY, 10, 2007, Kos Island. Proceedings. [S.1.]: Global NEST: University of the Aegean, 2007. p.863-867.

VALDEBENITO-SANHUEZA, R.M. Leveduras para o biocontrole de fitopatógenos. In: MELO, I.S. de; AZEVEDO, J.L. Controle biológico. Jaguariúna: Embrapa Meio Ambiente, 2000. p.41-55.

WIT, J.P.W.; KIEVITSBOSH, R.A.; BETTIOL, W. Integração de métodos físicos e biológicos para o controle de doenças e pragas em lírio e espatifilo. In: BETTIOL, W.; MORANDI, M.A.B. (Ed.). Biocontrole de doenças de plantas: uso e perspectivas. Jaguariúna: Embrapa Meio Ambiente, 2009. p.331-336.

ZANARDO, N.M.T.; PASCHOLATI, S.F.; FIALHO, M.B. Resistência de plântulas de pepineiro a Colletotrichum lagenarium induzida por frações de extrato de Saccharomyces cerevisiae. Pesquisa Agropecuária Brasileira, v.44, p.1499-1503, 2009.

Recebido em 14 de dezembro de 2009 e aprovado em 31 de maio de 2010 